\title{
Major histocompatibility locus genetic markers of beryllium sensitization and disease
}

\author{
C. Saltini*, L. Richeldi", M. Losi”, M. Amicosante ${ }^{\Uparrow}$, C. Voorter ${ }^{+}$, E. van den Berg-Loonen ${ }^{+}$, \\ R.A. Dweik ${ }^{\S}$, H.P. Wiedemann ${ }^{\S}$, D.C. Deubner ${ }^{f}$, C. Tinelli**
}

Major histocompatibility locus genetic markers of beryllium sensitization and disease. C. Saltini, L. Richeldi, M. Losi, M. Amicosante, C. Voorter, E. van den Berg-Loonen, R.A. Dweik, H.P. Wiedemann, D. C. Deubner, C. Tinelli. (C) ERS Journals Ltd 2001. ABSTRACT: Hypersensitivity to beryllium (Be) is found in $1-16 \%$ of exposed workers undergoing immunological screening for beryllium disease using the beryllium lymphocyte proliferation test (BeLPT). However, only $\sim 50 \%$ of BeLPT-positive workers present with lung granulomas (i.e. berylliosis). As berylliosis is associated with the human leukocyte antigen (HLA)-DP supratypic marker DPGlu69, the authors asked whether this marker is differentially associated with disease presentation.

A population of 639 workers from a beryllium factory undergoing BeLPT screening was evaluated in a nested case-control study for the prevalence of HLA-DPGlu69, the HLA-DPB1, HLA-DQ and HLA-DR alleles and of the biallelic tumour necrosis factor (TNF)- $\alpha$ polymorphism TNF- $\alpha-308$ in 23 individuals presenting as "sensitized" (i.e. BeLPT-positive without lung granulomas) and in 22 presenting as "diseased" (i.e. BeLPT-positive with granulomas in the lung biopsy).

The HLA-DPGlu69 marker was associated with "disease" (odds ratio (OR) 3.7, $\mathrm{p}=0.016,95 \%$ confidence interval $(\mathrm{CI}) \mathbf{1 . 4}-10.0$ ), whilst the high TNF- $\alpha$ productionrelated TNF- $\alpha-308 * 2$ marker was associated with both a positive BeLPT (OR 7.8, corrected $p<0.0001,95 \%$ CI 3.2-19.1) with no difference between "sensitization" and "disease". Furthermore, the HLA-DRArg74 marker was associated with "sensitization" without disease (OR 3.96, $\mathrm{p}=0.005,95 \%$ CI 1.5-10.1).

The data indicate that tumour necrosis factor- $\alpha$, human leukocyte antigen-DR and human leukocyte antigen-DP markers play different roles in beryllium sensitization and granuloma formation in beryllium-exposed workers.

Eur Respir J 2001; 18: 677-684.

\begin{abstract}
*Division of Respiratory Diseases of the University of Rome "Tor Vergata" at the National Institute for Infectious Diseases (INMI), Spallanzani Hospital, Rome, Italy. " Division of Pneumology, Policlinico, Modena, Italy. Laboratory of Clinical Pathology, INMI, Spallanzani Hospital, and the Dept of Cell Biology, University of "Tor Vergata", Rome, Italy. ${ }^{+}$Tissue Typing Laboratory, University Hospital Maastricht, Maastricht, the Netherlands. ${ }^{8}$ Pulmonary and Intensive Care, Cleveland Clinic Foundation, Cleveland, OH, USA. ${ }^{f}$ Medical Dept, Brush Wellman Inc., Elmore, $\mathrm{OH}$, USA. **Biostatistics Unit, IRCCS San Matteo, Pavia, Italy.
\end{abstract}

Correspondence: C. Saltini, Divisione di Malattie Respiratorie, Ospedale L. Spallanzani-I.R.C.C.S., via Portuense, 29200149 , Roma, Italy.

Fax: 390655170413

Keywords: Berylliosis genetic susceptibility human leukocyte antigen-DPGlu69 human leukocyte antigen-DR tumour necrosis factor- $\alpha$

Received: December 122000

Accepted after revision June 102001

This work was supported by grants DE-FG02-93ER61714 and ER6171410040580000196 from the Dept of Energy of the USA and grant 99060855594 from MURST, Italy.
Hypersensitivity to beryllium (Be) in workers exposed to Be dusts and fumes is the cause of a spectrum of reactions ranging from acute pneumonitis to berylliosis, a chronic granulomatous disease primarily affecting the lung [1].

Following the observation that blood T-cells of berylliosis patients proliferate in response to $\mathrm{Be}$ in vitro, a beryllium-stimulated blood lymphocyte proliferation test (BeLPT) has been developed to identify Be hypersensitive workers [2]. Screening programmes including the BeLPT and a lung transbronchial biopsy (TBB) showing noncaseating granulomas to diagnose berylliosis, have been effective in the earlier identification of affected individuals, as "screening" identified berylliosis cases showed milder disease than those identified upon clinical complaints or the finding of an abnormal chest radiograph [3]. Among the subjects showing a positive blood BeLPT, only $40-60 \%$ presented with a TBB positive for granulomas (i.e. berylliosis). A yet undetermined fraction of those with a negative TBB may eventually develop lung granulomas [4].

Berylliosis risk has been consistently associated with the expression of the supratypic human leukocyte antigen (HLA)-DPB1Glu69 (DPGlu69) marker, a marker that has been found to be expressed in $84-97 \%$ of disease cases in three separate studies [5-7], and that has been shown to function as the restriction element for Be presentation to Be-specific T-cell clones from HLA-DPGlu69-positive subjects 
with berylliosis (i.e. as the immune response gene of the Be-specific T-cell reaction of berylliosis) [8].

Disease presentation has been associated with major histocompatibility complex (MHC) locus gene markers in sarcoidosis, a granulomatous disorder similar to berylliosis, where spontaneously resolving hilar adenopathy has been associated with HLA-DR3 and chronic fibrosing lung disease with HLA-DR5 [9]. In this context, it was hypothesized that the DPGlu69, as well as other MHC markers, could be associated with disease presentation in Be-sensitized workers. Hence, a case-control study was designed including all BeLPT-positive subjects who were identified in the course of the screening of a large beryllium manufacturing plant. This sensitized group was further subdivided into: 1) a blood BeLPT-positive, TBBnegative subject or "sensitized" subgroup and 2) a BeLPT-positive, TBB-positive subject or "disease case" subgroup.

\section{Methods}

\section{Study population and case definition}

A population of 639 individuals from a beryllium manufacturing plant in Midwestern USA was enrolled after informed consent into a genetic study for susceptibility to berylliosis, in conjunction with the enrollment into a beryllium disease surveillance programme carried out by the plant's Medical Department, which included blood BeLPT carried out in two laboratories following published protocols [4]. This population had been described previously by KreIss et al. [10]. For the purpose of the present study, individuals with two abnormal BeLPTs in two separate blood samples were defined as BeLPTpositive or "sensitized" and were offered medical evaluation. The diagnosis of berylliosis was established upon a fibreoptic bronchoscopic TBB showing noncaseating granulomas. Individuals with a single abnormal BeLPT and "sensitized" individuals who declined medical evaluation were not included in the study. Twenty-three BeLPT-positive TBB-negative individuals were identified and defined as "sensitized"; they included 21 males and two females, mean \pm SD age $42 \pm 9 \mathrm{yrs}$, average years of employment $14 \pm 9$, all Caucasians. Twenty-two BeLPT-positive TBBpositive individuals were identified and defined as "disease cases"; they included 21 males and one female, mean \pm sD age $41 \pm 8$ yrs, average years of employment $15 \pm 6,20$ Caucasians and two AfricanAmericans. Ninety-three Be-exposed BeLPT-negative individuals were randomly selected from the whole Be-LPT-negative workers on the basis of a nested case-control study design, and therefore evaluated as controls; they included 78 males and 15 females, mean \pm sD age $44 \pm 9$ yrs, average years of employment $16 \pm 11,88$ Caucasians, two Hispanics, two AfricanAmericans, one Asian. The sample of the control population was selected on a 1:2 ratio and on the basis of previously published HLA-DP gene association data, in order to assure a sufficient statistical power to the study. The "sensitized" individuals and the "disease cases" were not statistically different from the control group for sex, age, time on the job and race.

\section{Genetic studies}

The study population was evaluated for the frequencies of two tumour necrosis factor (TNF)- $\alpha$ alleles (-308 biallelic polymorphism), TNF- $\alpha-308 * 1$ and TNF- $\alpha-308 * 2$ and HLA class II (HLA-DPB1, HLA-DQB1, HLA-DRB1 and HLA-DRB3/4/5) alleles.

\section{Tumour necrosis factor- $\alpha$ gene polymorphism analysis}

The analysis of the biallelic polymorphism ( $\mathrm{G}$ to $\mathrm{A})$ at position -308 of the promoter of the TNF- $\alpha$ gene was carried out by polymerase chain reaction (PCR) amplification of $500 \mathrm{ng}$ of genomic deoxyribonucleic acid (DNA) using the primers TNF- $\alpha-308-A$ (CA AACACAGGCCTCAGGACT) and TNF- $\alpha-308-\mathrm{B}$ (AGGGAGCGTCTGCTGGCTG) with the following PCR cycles (GeneAmp 9600, Perkin Elmer Corporation, Roche Molecular Systems, Branchburg, CT, USA): one denaturation cycle $\left(95^{\circ} \mathrm{C}\right.$ for $1 \mathrm{~min}$ with a pause at $80^{\circ} \mathrm{C}$ for the hot start technique), 30 amplification cycles $\left(94^{\circ} \mathrm{C}\right.$ for $30 \mathrm{~s}, 55^{\circ} \mathrm{C}$ for $30 \mathrm{~s}$, $72^{\circ} \mathrm{C}$ for $\left.30 \mathrm{~s}\right)$, one extension cycle $\left(72^{\circ} \mathrm{C}\right.$ for $\left.7 \mathrm{~min}\right)$. The expected molecular weight of the amplified product was 545 base pairs (bp). Ten $\mu \mathrm{L}$ of the PCR product were then analysed on a $2 \%$ agarose gel stained with ethidium bromide. Twenty $\mu \mathrm{L}$ of the PCR product were probed using the oligonucleotide probes TNF-1 (Biotin-AGGGGCATGGGGACGGG) and TNF-2 (Biotin-AGGGGCATGAGGACGGG) in the nonradiometric hybridization DNA enzyme immunoassay (DEIA) method (Gen-ETI-K DEIA, Sorin Biomedica, Saluggia, Vercelli, Italy). The DEIA experimental conditions were as follows: PCR product: $20 \mu \mathrm{L}$ PCR product per well; probe concentration: $5 \mathrm{ng}$ probe per well; hybridization conditions: $1 \mathrm{~h}$ at $50^{\circ} \mathrm{C}$. The hybridization results were obtained as optical density values on an enzyme-linked immunosorbent assay (ELISA) fast reader (Sorin Biomedica). In order to confirm the hybridization results, 20 DNA samples were sequenced for the TNF- $\alpha-308$ genotyping. Briefly, $250 \mathrm{ng}$ of genomic DNA were PCR amplified with the primers TNF308AM13 (TGTAAAACGACGGCCAGTGAAACAGACCAC AGACCTG) and TNF308BB (Biotin-CTTCTGTC TCGGTTTCTTC) using one denaturation cycle $\left(95^{\circ} \mathrm{C}\right.$ for $\left.1 \mathrm{~min}\right), 35$ amplification cycles $\left(94^{\circ} \mathrm{C}\right.$ for $1 \mathrm{~min}, 54^{\circ} \mathrm{C}$ for $20 \mathrm{~s}, 72^{\circ} \mathrm{C}$ for $20 \mathrm{~s}$ ), one extension cycle $\left(72^{\circ} \mathrm{C}\right.$ for $\left.7 \mathrm{~min}\right)$ to generate a $250 \mathrm{bp}$ fragment. The PCR product was directly cycle-sequenced with the fluorescein-labelled M13 universal sequencing primer (GTAAAACGACGGCCAGT), (Pharmacia Biotech, Uppsala, Sweden) (3 pmol) using the Thermo Sequenase fluorescent-labelled primer cycle sequencing kit (Amersham Life Sciences, Little Chalfont, UK) for 20 PCR cycles $\left(98^{\circ} \mathrm{C}\right.$ for $30 \mathrm{~s}$, $60^{\circ} \mathrm{C}$ for $30 \mathrm{~s}, 72^{\circ} \mathrm{C}$ for $30 \mathrm{~s}$ ) in conjunction with the AutoLoad Solid Phase Sequencing Kit (Pharmacia 
Biotech), following the manufacturer's instructions and analysed on an automated laser fluorescence (ALF) DNA sequencer (Pharmacia Biotech).

\section{Typing of human leukocyte antigen-DRB1, -DRB3/4/5 and $-D Q B 1$ alleles}

For high-resolution typing of HLA-DRB1, -DRB3/ 4/5 and -DQB1, either PCR with sequence-specific primers (PCR-SSP) or sequence-based typing (SBT) was used. First, a low resolution typing was performed by means of group-specific amplification of exon 2 using a $5^{\prime}$ or $3^{\prime}$ specific primer in combination with a generic primer. Depending on the allele groups that were identified, high-resolution typing was performed by a subsequent PCR-SSP using additional primer mixes, or by sequence-based typing [11, 12]. For high-resolution typing of HLA-DPB1, sequencebased typing was used in all instances [13]. Highresolution typing for DRB1/3/4/5, DQB1 and DPB1 was performed for all individuals studied, except in nine cases where high resolution of DRB3/4/5 and/or DQB1 was not possible due to a shortage of material. Since no subtype differences are located in exon 2 of DQB $1 * 02$ only low-resolution typing was performed.

The sequence-based typing method for the HLA class II alleles was carried out as described previously [11-13]. For SBT of all class II genes, a PCR product was generated by amplification of exon 2 and, if needed, exon 3 using amplification and sequencing primers located at the $5^{\prime}$ and $3^{\prime}$ end of exon 2 or in introns 1 and 2. Amplification was performed in a final volume of $60 \mu \mathrm{L}$ consisting of $600 \mathrm{ng}$ DNA, PCR buffer $(10 \mathrm{mM}$ Tris-HCl, pH 8.3; $50 \mathrm{mM} \mathrm{KCl}$; $\left.1.5 \mathrm{mM} \mathrm{MgCl}_{2}\right), 5 \%$ glycerol, $6 \mu \mathrm{g}$ cresol red, $200 \mu \mathrm{M}$ each deoxyribonucleoside triphosphate (dNTP), 20 pmol biotinylated primer, $40 \mathrm{pmol}$ unlabelled primer and 2.0 U AmpliTaq DNA polymerase (Perkin-Elmer Corporation). For amplification of DQB1, 1\% dimethyl sulphoxide (DMSO) was added to the PCR reaction mixture. PCR amplifications were carried out in a Gene Amp PCR System 9600 (Perkin-Elmer Corporation). The PCR profiles consisted of an initial denaturation at $94^{\circ} \mathrm{C}(2 \mathrm{~min}), 10$ cycles of $10 \mathrm{~s}$ at $94^{\circ} \mathrm{C}, 1 \mathrm{~min}$ at $65^{\circ} \mathrm{C}$ and finally 20 cycles (for DRB1/3/4/5 and DQB1) or 30 cycles (for DPB1) of $10 \mathrm{~min}$ at $94^{\circ} \mathrm{C}, 50 \mathrm{~s}$ at $61^{\circ} \mathrm{C}$ and $30 \mathrm{~s}$ at $72^{\circ} \mathrm{C}$, followed by $10 \mathrm{~min}$ at $72^{\circ} \mathrm{C}$. The sequencing reaction was based on a solid phase approach using attachment of the biotinylated PCR product to streptavidincoated beads. The sequencing reaction was performed using the Autoread Sequencing Kit (Amersham Pharmacia), according to the suppliers protocol. The sequencing reaction mixture was analysed on a Pharmacia ALFexpress DNA sequencer (Pharmacia Biotech) using a $6 \%$ polyacrylamide/7 $\mathrm{M}$ urea gel. The gel was run at $1,500 \mathrm{~V}, 60 \mathrm{~mA}$ and $25 \mathrm{~W}$ at $5^{\circ} \mathrm{C}$ for $6 \mathrm{~h}$. After manual evaluation of the processed data, the determination of the HLA subtype was performed with the use of the HLA-Sequityper software (Pharmacia Biotech).
Analysis of the human leukocyte antigen-DPB Glu69 marker

In addition to SBT, genomic DNA samples were screened for the HLA-DPB1*AAG $\rightarrow$ GAG polymorphism coding the lysine to glutamate 69 amino acid residue using a simple hybridization test designed so that the sensitivity and specificity of each test could be validated by discriminant analysis as already described [6].

\section{Statistical analysis}

HLA class II allele and phenotype distributions in berylliosis-affected, Be-sensitized and healthy exposed control groups were compared by means of univariate analysis using odds ratio (OR) and 95\% confidence interval (CI); probability values were calculated with the Fisher's exact test. In order to assess the relative strength of the different MHC associations with the disease and sensitization status, and to ascertain possible linkage disequilibria between the HLA-DP and HLA-DR markers and the TNF- $\alpha$ gene, the statistical method described by SVEJGAARD and RYDER [14] was applied.

The method is based on two-by-two tests of the various components of a two-by-four table. Briefly, the frequencies of the phenotypic combinations of the two genetic factors (the DPGlu69, the DRArg74 and the TNF- $\alpha-308 * 2$ markers) in patients and controls were calculated ("basic" table). These "basic" data were then analysed by means of various tests, i.e. twoby-two tables ("tests" table); for each test an OR was calculated using adequate modifications for "zero" entries and the statistical significance of the OR values was established by Fisher's exact test. Because this analysis involved multiple comparisons, the p-values were corrected; in particular, due to the fact that the association of the DPGlu69 marker was known before the present study, no corrections were done for this marker. On the contrary, p-values for the DRArg74 and the TNF- $\alpha-308 * 2$ markers have been corrected for the number of polymorphisms and the number of groups analysed. Due to the fact that no association data were available for the TNF- $\alpha-308$ polymorphism and berylliosis and no conclusive demonstration of linkage disequilibrium between HLA-DP and TNF- $\alpha$ was found to exist, the other comparisons were corrected for six or by nine, accordingly to the recommendations given by SVEJGAARD and RYDER [14].

In the "tests" table, a series of two-by-two comparisons represents various stratifications of the data for the genetic markers testing (in)dependent contributions to disease susceptibility (table 1, independent association), "interaction" of the factors, difference between the associations (table 1, A association, $\mathrm{B}$ association and difference between $\mathrm{A}$ and $B$ associations), the value of the combined action of the two factors (table 1, combined association) and linkage disequilibrium of the genetic factors in sensitized/patients and controls (table 1, association between $\mathrm{A}$ and $\mathrm{B}$ ). The tests performed were aimed to 
Table 1. -Quantification of the association and interaction levels between the human leukocyte antigen (HLA)-DPB1Glu69 (DPGlu69), the HLA-DRB1/B3Arg74 (DRArg74) and the tumour necrosis factor (TNF)- $\alpha-308^{\star} 2$ genetic markers in beryllium-sensitized individuals ("sensitized" subgroup) and in berylliosis patients ("disease case" subgroup)

\begin{tabular}{|c|c|c|c|c|c|c|c|c|c|c|}
\hline \multirow[t]{2}{*}{ Factor A $c f$. Factor B } & \multicolumn{2}{|c|}{$\begin{array}{l}\text { Independent } \\
\text { association }\end{array}$} & \multicolumn{2}{|c|}{$\underset{\text { association }}{\mathrm{A}}$} & \multicolumn{2}{|c|}{$\frac{\mathrm{B}}{\text { association }}$} & \multirow{2}{*}{$\begin{array}{c}\text { Difference } \\
\text { between A and } \\
\text { B associations } \\
+- \\
\text { versus } \\
-+\end{array}$} & \multirow{2}{*}{$\begin{array}{c}\begin{array}{c}\text { Combined } \\
\text { association }\end{array} \\
\begin{array}{c}++ \\
\text { versus } \\
--\end{array}\end{array}$} & \multicolumn{2}{|c|}{$\begin{array}{c}\text { Association } \\
\text { between A and B }\end{array}$} \\
\hline & A & B & $\begin{array}{c}++ \\
\text { versus } \\
-+\end{array}$ & $\begin{array}{c}+- \\
\text { versus } \\
--\end{array}$ & $\begin{array}{c}++ \\
\text { versus } \\
+-\end{array}$ & $\begin{array}{c}-+ \\
\text { versus } \\
--\end{array}$ & & & "Sensitized" & Controls \\
\hline \multicolumn{11}{|l|}{ "Sensitized" subgroup } \\
\hline $\begin{array}{l}\text { DPGlu69 } c f . \\
\text { DRArg74 }\end{array}$ & 0.9 & $3.9^{\#}$ & 0.4 & 2.2 & 1.3 & $7.9^{\#}$ & 0.3 & 2.9 & 0.2 & 1.4 \\
\hline $\begin{array}{c}\text { TNF- } \alpha-308 * 2 c f . \\
\text { DPGlu69 }\end{array}$ & $5.0^{\#}$ & 0.9 & 2.5 & $8.8^{\#}$ & 0.4 & 1.3 & $6.8^{\#}$ & 3.2 & 0.6 & 2.2 \\
\hline $\begin{array}{c}\text { TNF- } \alpha-308 * 2 c f . \\
\text { DRArg74 }\end{array}$ & $5.0^{\#}$ & $3.7^{\#}$ & 3.2 & $4.6^{\oplus}$ & 2.1 & 3.1 & $1.5^{\bullet}$ & $9.9^{\#}$ & 2.2 & 3.2 \\
\hline \multicolumn{11}{|l|}{ "Disease case" subgroup } \\
\hline $\begin{array}{c}\text { DPGlu69 } c f . \\
\text { DRArg74 }\end{array}$ & $3.5^{\bullet}$ & 0.9 & 3.3 & $3.4^{\oplus}$ & 0.9 & 0.9 & 3.7 & 3.0 & 1.3 & 1.4 \\
\hline $\begin{array}{l}\text { TNF- } \alpha-308 * 2 c f . \\
\text { DPGlu69 }\end{array}$ & $4.6^{\#}$ & $3.4^{\top}$ & 3.8 & 3.7 & 2.6 & 2.5 & 1.5 & $9.7^{\#}$ & 2.3 & 2.2 \\
\hline $\begin{array}{c}\text { TNF- } \alpha-308 * 2 c f . \\
\text { DRArg74 }\end{array}$ & $4.6^{\#}$ & 0.9 & 2.9 & $5.9^{\#}$ & 0.5 & 1.0 & $6.2^{\bullet}$ & 2.8 & 1.6 & 3.2 \\
\hline
\end{tabular}

Data are presented as odds ratios (ORs). ${ }^{\#}$ : $\mathrm{p}$-values are significant $(\mathrm{p}<0.05)$ after correction; ${ }^{\bullet}$ : $\mathrm{p}$-values $<0.05$ before, but not after correction. All other figures indicate nonsignificant $\mathrm{p}$-values.

verify various hypotheses and an interpretation is given based upon the significance values. According to SvejgaARD and Ryder [14], p-values 0.01-0.05 should be regarded as "probably significant" and only p-values $<0.01$ should be considered as "significant". In fact, the retrospective analysis of HLA-association studies suggests that only these latter p-values have been confirmed in multiple independent studies [14]. However, several authorities in the HLA-disease field [14] strongly recommend the use of phenotypic (or supratypic) markers instead of allelic frequencies for specific reasons: 1) to avoid the bias of increased statistical power determined by the artificial doubling of the population size inherent to allelic frequencies analysis (from $\mathrm{N}$ patients to $2 \times \mathrm{N}$ genes); 2) the phenotype analysis appears to be more appropriate because usually the gene product and not the gene itself is responsible for disease susceptibility or protection [14]. Accordingly, allelic variant analysis data are presented as phenotypic data and the above definitions of "probably significant" and "significant" are used throughout the manuscript.

\section{Results}

Human leukocyte antigen-DR, $-D Q$ and $-D P$ marker frequencies

The frequencies of HLA-DRB $1 * 0301$, HLADRB3*0101, HLA-DQB1*02 and HLA-DPB1*0501 alleles were higher in the "sensitized" subgroup, while HLA-DRB3*0301 was higher and HLA-DRB4*0103 was lower in the "disease case" subgroup (tables 2-5). None of the differences was statistically significant after correction for the number of alleles tested.
The inspection of the polymorphic amino acid residues in the sensitization-associated alleles HLADRB1*0301 and HLA-DRB3*0101 showed 82\%

Table 2.-Frequencies of the human leukocyte antigen (HLA)-DP alleles ${ }^{\#}$ in the study populations

\begin{tabular}{lccc}
\hline DPB1 alleles & Control & "Sensitized" & "Disease case" \\
\hline $0101^{\#}$ & $6(3.2)$ & $3(6.5)$ & $2(4.6)$ \\
0201 & $32(17.2)$ & $6(13.0)$ & $12(27.3)$ \\
0202 & $1(0.5)$ & $2(4.4)$ & $4(9.1)$ \\
0301 & $18(9.7)$ & $19(41.3)$ & $10(22.7)$ \\
0401 & $71(38.2)$ & $2(4.4)$ & $4(9.1)$ \\
0402 & $28(15.1)$ & $5(10.9)$ & $1(2.3)$ \\
0501 & $4(2.2)$ & $2(4.4)$ & $1(2.3)$ \\
0601 & $2(1.1)$ & & $1(2.3)$ \\
0901 & $5(2.7)$ & & $3(6.8)$ \\
1001 & $4(2.2)$ & $1(2.2)$ & $1(2.3)$ \\
1101 & $1(0.6)$ & $1(2.2)$ & $1(2.3)$ \\
1301 & $4(2.2)$ & & \\
1401 & $2(1.1)$ & $1(2.2)$ & $1(2.3)$ \\
1501 & & $1(2.2)$ & $2(4.6)$ \\
1601 & $1(0.6)$ & & $1(2.3)$ \\
1701 & $1(0.6)$ & & \\
1801 & $1(0.6)$ & $2(4.4)$ & \\
1901 & $2(1.1)$ & $1(2.2)$ & \\
2001 & $1(0.6)$ & & \\
2301 & $1(0.6)$ & & \\
3501 & $1(0.6)$ & & \\
$7701^{\bullet}$ & & & \\
$7801^{\bullet}$ & & &
\end{tabular}

Data are presented as $\mathrm{n}(\%)$. *: the allele DPB $1 * 0101$ includes the allele splits $* 01011$ (controls: five alleles, 2.69\% allele frequency) and $* 01012$ (controls: one allele, $0.54 \%$ allele frequency) expressing all the same amino acid sequence; : these HLA-DPB1 alleles have been identified in this study population (see [15]). 
Table 3.-Frequencies of the human leukocyte antigen (HLA)-DQ alleles in the study populations

\begin{tabular}{lccl}
\hline DQB1 alleles & Control & "Sensitized" & "Disease case" \\
\hline $02^{\#}$ & $30(16.1)$ & $15(32.6)$ & $5(11.4)$ \\
0201 & $1(0.5)$ & $1(2.2)$ & $2(4.5)$ \\
0202 & $6(3.2)$ & $1(2.2)$ & \\
$03^{*}$ & $35(18.8)$ & $6(13.0)$ & $7(15.9)$ \\
0301 & $20(10.7)$ & $3(6.5)$ & $1(2.3)$ \\
0302 & $9(4.8)$ & $1(2.2)$ & $2(4.5)$ \\
0303 & $1(0.5)$ & & \\
0304 & $6(3.2)$ & $1(2.2)$ & \\
0402 & $1(0.5)$ & $1(2.2)$ & $5(11.4)$ \\
05 & $14(7.5)$ & $2(4.4)$ & $1(2.3)$ \\
0501 & $3(1.6)$ & $1(2.2)$ & $1(2.3)$ \\
0502 & $6(3.2)$ & $2(4.4)$ & $2(4.5)$ \\
0503 & $3(1.6)$ & $1(2.2)$ & $7(15.9)$ \\
06 & $2(1.1)$ & & $4(9.1)$ \\
0601 & $24(12.9)$ & $8(17.4)$ & $5(11.4)$ \\
0602 & $13(7.0)$ & & $2(4.5)$ \\
0603 & $1(0.5)$ & $2(4.4)$ & \\
0603 & $9(4.8)$ & & \\
0604 & $2(1.1)$ & & \\
0605 & 0609 & &
\end{tabular}

Data are presented as $\mathrm{n}(\%) .{ }^{*}$ : for $\mathrm{DQB} 1 * 02$, no subtype differences are located in exon 2 and therefore only low resolution typing resulting are given; ${ }^{\uparrow}$ : for 15 alleles (from nine subjects), high-resolution typing of DQB1 was not possible due to shortage of material, and the data obtained allowed the DQ serotype assignment only.

homology, suggesting that shared polymorphic residues could in fact be associated with sensitization to Be. The comparison between polymorphic residues expressed by the alleles, positively or negatively associated with disease or sensitization, showed that residues DRTyr26 and DRArg74 were unique to sensitization-associated alleles.

Strikingly, the frequency of the DRArg74 marker was significantly higher in the "sensitized" subgroup than in controls (OR 3.96, $\mathrm{p}=0.005,95 \%$ CI 1.5-10.1). In contrast, in the "disease case" subgroup it was similar to controls (OR 0.89, nonsignificant, 95\% CI 0.31-2.6; fig. 1). Also, the DRArg74 marker frequency in the "sensitized" subgroup was significantly higher than in the "disease case" subgroup ( $\chi^{2}$ test, $\left.\mathrm{p}=0.044\right)$.

Consistent with previous study results, the frequency of the DPGlu69 marker was significantly higher in the "disease case" subgroup than in controls (OR 3.7, $\mathrm{p}=0.016,95 \%$ CI 1.4-10.0; fig. 1). In contrast, its frequency in the "sensitized" subgroup was not different from that in controls (OR 0.89, nonsignificant, 95\% CI $0.30-2.22)$. As expected, the frequencies of several DPGlu69-positive HLA-DPB1 alleles were also increased in the "disease case" subgroup: HLA-DPB1*0201 27.3\% (controls: 17.2\%), *0601 2.3\% (controls: 1.1\%), *0901 2.3\% (controls: $0 \%$ ), *1001 6.8\% (controls: $2.7 \%$ ), *1601 2.3\% (controls: $0 \%$ ), *1701 $4.6 \%$ (controls: $0 \%$ ), *1901 2.3\% (controls: $0.5 \%$ ). Similarly, the frequencies of the DPGlu69-positive HLA-DPB1 allele phenotypes were also increased in the "disease case" subgroup (table 6). None of these differences, possibly due to the small
Table 4.-Frequencies of the human leukocyte antigen (HLA)-DRB1 alleles in the study populations

\begin{tabular}{|c|c|c|c|}
\hline DRB1 alleles & Control & "Sensitized" & "Disease case" \\
\hline $01^{\#}$ & & $1(2.2)$ & \\
\hline 0101 & $13(7.0)$ & $2(4.4)$ & $4(9.1)$ \\
\hline 0103 & $1(0.5)$ & & $1(2.3)$ \\
\hline 0301 & $14(7.5)$ & $14(30.4)$ & $4(9.1)$ \\
\hline 0302 & $1(0.5)$ & & \\
\hline $04^{\#}$ & $1(0.5)$ & & \\
\hline 0401 & $20(10.7)$ & $1(2.2)$ & \\
\hline 0402 & $1(0.5)$ & $1(2.2)$ & \\
\hline 0404 & $4(2.2)$ & $2(4.4)$ & $1(2.3)$ \\
\hline 0405 & $3(1.6)$ & $1(2.2)$ & \\
\hline 0407 & $1(0.5)$ & & \\
\hline 0408 & $2(1.1)$ & & \\
\hline 0410 & $1(0.5)$ & & \\
\hline $07^{\#}$ & & $1(2.2)$ & \\
\hline 0701 & 24 (12.9) & $2(4.4)$ & $5(11.4)$ \\
\hline 0801 & $4(2.2)$ & $1(2.2)$ & \\
\hline 0806 & & & $2(4.5)$ \\
\hline 0810 & & $1(2.2)$ & \\
\hline 0901 & & $1(2.2)$ & \\
\hline 1001 & $1(0.5)$ & & \\
\hline 1101 & $17(9.1)$ & $2(4.4)$ & $4(9.1)$ \\
\hline 1102 & $2(1.1)$ & $1(2.2)$ & $1(2.3)$ \\
\hline 1103 & $5(2.7)$ & & $1(2.3)$ \\
\hline 1104 & $3(1.6)$ & & $1(2.3)$ \\
\hline 1201 & $1(0.5)$ & $1(2.2)$ & \\
\hline 1301 & $15(8.1)$ & $1(2.2)$ & $6(13.6)$ \\
\hline 1302 & $11(5.9)$ & $2(4.4)$ & 7 (15.9) \\
\hline 1303 & $4(2.2)$ & & \\
\hline 1401 & $6(3.2)$ & $2(4.4)$ & $1(2.3)$ \\
\hline 1406 & $1(0.5)$ & & \\
\hline 1501 & $24(12.9)$ & $8(17.4)$ & $5(11.4)$ \\
\hline 1502 & 3 (1.6) & & \\
\hline 1601 & $3(1.6)$ & $1(2.2)$ & $1(2.3)$ \\
\hline
\end{tabular}

Data are presented as $\mathrm{n}(\%) .{ }^{*}$ : for three alleles (from two subjects), high-resolution typing of DRB1 was not possible due to shortage of material, and the data obtained allowed the DR serotype assignment only.

size of the study group, were statistically significant in comparison to the phenotypic frequencies in the control group.

Table 5.-Frequencies of the human leukocyte antigen (HLA)-DRB3*, 4*, 5* alleles in the study populations

\begin{tabular}{|c|c|c|c|}
\hline DRB alleles & Control & "Sensitized" & "Disease case" \\
\hline $3 * 0101$ & $19(10.3)$ & $16(34.8)$ & $5(11.4)$ \\
\hline $3 * 0201$ & $3(1.6)$ & & \\
\hline $3 * 0202$ & $53(28.8)$ & $7(15.2)$ & $16(36.4)$ \\
\hline $3 * 0301$ & $13(7.1)$ & $2(4.4)$ & $8(18.2)$ \\
\hline $4^{* \#}$ & $6(3.3)$ & $2(4.4)$ & \\
\hline $4 * 01^{\#}$ & $1(0.5)$ & & \\
\hline $4 * 0101$ & 14 (7.6) & $2(4.4)$ & $4(9.1)$ \\
\hline $4 * 0103$ & $43(23.4)$ & $6(13.0)$ & $3(6.8)$ \\
\hline $5^{* \#}$ & $2(1.1)$ & & \\
\hline $5 * 0101$ & 25 (13.6) & $10(21.7)$ & 6 (13.6) \\
\hline $5 * 0102$ & $2(1.1)$ & & \\
\hline $5 * 0202$ & $3(1.6)$ & $1(2.2)$ & $2(4.5)$ \\
\hline
\end{tabular}

Data are presented as $\mathrm{n}(\%)$. ${ }^{\#}$ : for nine alleles (from seven subjects) high-resolution typing of DRB4* or DRB5* allele was not possible due to shortage of material, and the data obtained allowed the DR serotype assignment only. 


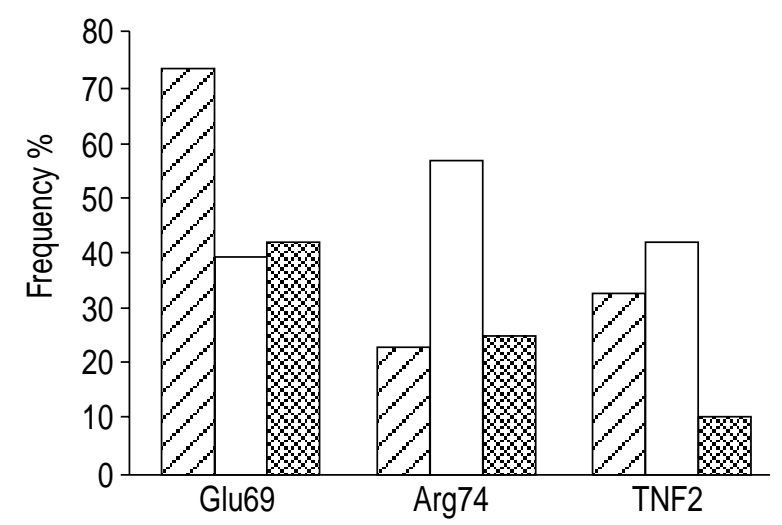

Fig. 1.-Frequencies $(\%)$ of the genetic markers tumour necrosis factor (TNF)- $\alpha-308 * 2$, human leukocyte antigen (HLA)-DRArg74 and HLA-DPGlu69 in the "disease case" ( $\square)$ the "sensitized" ( $\square$ ) and the control (网) groups.

\section{Tumour necrosis factor- $\alpha-308$ polymorphism analysis}

The frequency of the TNF- $\alpha-308^{*} 2$ allele was significantly increased in the whole BeLPT-positive group compared to BeLPT-negative controls (BeLPTpositive 51.1\% versus BeLPT-negative 16.1\%, OR 7.8, corrected $\mathrm{p}<0.0001,95 \%$ CI 3.2-19.1). When the "sensitized" and the "disease case" subgroups were compared separately to the controls, the frequency of TNF- $\alpha-308 * 2$ was significantly higher in both subgroups (fig. 1), and it was similar in the "sensitized" and the "disease case" subgroup ( $\chi^{2}$ test $=1.8$, nonsignificant; fig. 1).

\section{Analysis for gene interactions}

The evaluation of the interaction between the DPGlu69, DRArg74 and TNF- $\alpha-308 * 2$ markers, using the analysis of multiple HLA associations with disease described by SvejgaARD and Ryder [14], showed a positive interaction between TNF- $\alpha-308 * 2$ and DRArg74 in the association with the "sensitized" subgroup (table 1, combined association) in the absence of linkage disequilibrium (table 1, association between $\mathrm{A}$ and $\mathrm{B}$ ), but no interaction in the association with the "disease case" subgroup (table 1, combined association). Conversely, while there was no interaction between TNF- $\alpha-308^{*} 2$ and DPGlu69 in the association of the TNF- $\alpha-308 * 2$ marker with the "sensitized" subgroup (table 1, combined association) there was a positive interaction in the association with the "disease case" subgroup (table 1, combined association), in the absence of linkage disequilibrium (table 1, association between $\mathrm{A}$ and $\mathrm{B}$ ). In addition, there was an association of DPGlu69 with the "sensitized" DRArg74-negative subjects (table 1, B association -+ versus --), but no positive interaction between the two markers either in the "sensitized" or the "disease case" subgroups (table 1, A association ++ versus -+ ).

\section{Discussion}

Current concepts of the pathogenesis of berylliosis are that the granulomatous reaction to inhaled Be will develop, after a variable latency period, in the majority, albeit not all, of individuals who develop a T-cell reaction to $\mathrm{Be}$ [4]. Previous studies have shown that in individuals with the granulomatous reaction, the reaction to $\mathrm{Be}$ is maintained by the activation of CD4+ type-1 T-cells, which are capable of recognizing Be presented by class II MHC molecules [1]. Studies from the authors' laboratory and from others have shown that susceptibility to berylliosis is associated with an HLA-DP marker, the supratypic marker HLA-DPBGlu69 [5-7], although WANG et al. [7] have claimed that susceptibility to beryllium disease is associated with rarer HLA-DPB1Glu69-positive alleles through a yet to be defined mechanism. This study shows that the supratypic marker DPGlu69 is associated with the presentation as "disease case"

Table 6. - Frequencies of the Glu69-positive and Glu69-negative phenotypes and of the Glu69-positive human leukocyte antigen (HLA)-DPB1 alleles in the "sensitized" subgroup, the "disease case" subgroup and in controls

\begin{tabular}{lccc}
\hline Phenotypic frequencies & "Sensitized" & "Disease case" & Control \\
\hline Patients n & 23 & 22 & 93 \\
Glu69-negatives & $22(95.7)$ & $17(77.3)$ & $9(96.8)$ \\
Glu69-positives & $9(39.1)$ & $16(72.7)$ & $37(39.8)$ \\
Glu69-positive HLA-DPB1 alleles & & & \\
HLA-DPB1*0201 & $5(21.7)$ & $8(36.4)$ & $27(29.0)$ \\
HLA-DPB1*0202 & $0(0)$ & $0(0)$ & $1(1.1)$ \\
HLA-DPB1*0601 & $2(8.7)$ & $1(4.5)$ & $2(2.2)$ \\
HLA-DPB1*0901 & $0(0)$ & $1(4.5)$ & $0(0)$ \\
HLA-DPB1*1001 & $0(0)$ & $3(13.6)$ & $5(5.4)$ \\
HLA-DPB1*1301 & $1(4.3)$ & $1(0)$ & $1(1.1)$ \\
HLA-DPB1*1601 & $1(4.3)$ & $2(9.5)$ & $0(0)$ \\
HLA-DPB1*1701 & $0(0)$ & $1(4.5)$ & $0(0)$ \\
HLA-DPB1*1901 & $0(0)$ & $1.1)$ \\
\hline
\end{tabular}

Data are presented as $\mathrm{n}(\%)$ unless otherwise stated. In this analysis, the number of subjects carrying Glu69-positive phenotypes (Glu69-positives) does not correspond to the number of subjects carrying Glu69-positive HLA-DPB1 alleles in the same column. Subjects homozygous for Glu69, due to the carriage of two different Glu69-positive HLA-DPB1 alleles, are listed once in the "Glu69-positives" row and twice in the Glu69-positive HLA-DPB1 alleles rows, once for each of the alleles carried. ": $\mathrm{p}=0.023$ versus "sensitized" and $\mathrm{p}=0.05$ versus controls. 
(i.e. with a profusion of lung granulomas sufficient for TBB detection of the pathological alteration), but it is not associated with the presentation as "sensitized" (i.e. with undetectable lung granulomas), which instead appears to be associated with other MHC class II markers, possibly the supratypic marker DRArg74. Finally, both "sensitization" and "disease case" are strongly associated with the MHC locus cytokine gene TNF- $\alpha$, TNF- $\alpha-308 * 2$ marker.

The association of different HLA markers with disease presentation is reminiscent of a number of immunogenetic observations. In leprosy, MT1, MB1 and DC1 are associated with lepromatous leprosy [15], while DR3 and the amino acid residues DRB1Arg13, 70 and 71 are associated with tuberculoid leprosy [16]. In sarcoidosis, DR3 is associated with presentation as spontaneously resolving stage I disease, while DR4 and DR5 are associated with presentation as progressive stage III disease [9]. In schistosomiasis japonica, Dw19, DRw13 and DQw1 are associated with the presence of liver fibrosis, and Dw12, DR2, DQw1, DPA1*0301 and DPB1*0201 with its absence $[17,18]$.

Current concepts of HLA disease association are that the amino acid residues implicated in peptide binding to HLA-DR molecules for presentation to the T-cell antigen receptor [19] are also associated with several immune disorders as susceptibility factors [14]. In their recent study, WANG et al. [7] found a significant increase in the frequency of the rare alleles HLA-DPB1*1701, *0901 and *1001, along with a decrease of the common allele HLA-DPB $1 * 0201$ in an American population of beryllium disease patients and suggested that these, and not the supratypic marker that they shared, represented the disease marker. In the present study, increased frequencies of Glu69 HLA-DPB1 alleles, including HLADPB $1 * 0201$, were also found both in the "sensitized" and the "disease case" groups. However, the demonstration by LOMBARDI et al. [8] that the Glu69 residue of the HLA-DP $\beta$ chain is directly involved in presentation of Be to the T-cells of HLA-DPBGlu69 subjects with berylliosis, consistent with the observation that the HLA-DPGlu69 residue is important in autoimmunity and alloreactivity [20] and with the finding of oligoclonal beryllium-reactive T-cells [21], strongly indicates that the sequence coding for the HLA-DPB1 amino acid residue Glu69 is not only a supratypic marker but it is the immune response gene of berylliosis. Interestingly, the observation that HLA-DPGlu69 is associated with susceptibility to hard metal lung disease and that cobalt directly interacts with the HLA-DPB1Glu69 molecule [22] suggests that this HLA-DP molecule is endowed with the ability of interacting with certain metal cations, possibly through direct binding.

The DRArg74 residue, which is involved in peptide binding by HLA-DR molecules [19], may also play a direct role in the immune response to Be. However, no evidence is yet available for a role of HLA-DRB3 molecules in Be presentation. On the other hand, in the context that interferon gamma (IFN- $\gamma$ ) plays a pivotal role in granuloma formation and is overexpressed in response to $\mathrm{Be}$ in vitro [23], the apparent "protective" effect of DRArg74 on disease pathogenesis may be due to association of the HLA-DR3 alleles (i.e. DRArg74) with low production of IFN- $\gamma$ [24]. Since the authors only assessed the association of DRArg74 with TNF- $\alpha-308 * 2$ and DPGlu69, a linkage of DRArg74 with low IFN- $\gamma$-stimulated production cannot be ruled out.

With regard to the TNF- $\alpha-308 * 2$ marker, it is known that TNF-308*2 is strongly associated with the high TNF- $\alpha$ production in subjects carrying the HLA-A1, -B8 and -DR3 haplotype. Current concepts are that elevated $\mathrm{TNF}-\alpha$ production associated with the -308 polymorphism may alter the course of an immune response, thus increasing the risk of disease development [25]. This marker has been associated with susceptibility to sarcoidosis [26] and silicosis [27]. It may be hypothesized that TNF- $\alpha$ plays an initiating role in $\mathrm{Be}$ sensitization since it is known that TNF- $\alpha$ messenger ribonucleic acid (mRNA) and protein expression are increased upon Be stimulation of the $\mathrm{H} 36.12 \mathrm{j}$ mouse macrophage cell line [28], a process similar to experimental nickel-contact dermatitis where nickel-upregulated keratinocyte TNF- $\alpha$ production plays a role in skin sensitization [29].

In summary, the present study confirms that the human leukocyte antigen-DPGlu69 marker is associated with beryllium disease and identifies another gene marker, tumour necrosis factor- $\alpha-308 * 2$, also associated with disease risk. In addition, it suggests that more than one major histocompatibility complex gene may be involved in the determination of disease susceptibility, playing different and even contrasting roles in disease pathogenesis. In the context that genetic screening for disease risk could be costeffective [30], the characterization of diseaseassociated genes may lead to the identification of reliable markers of disease risk for the prevention of berylliosis.

\footnotetext{
Acknowledgements. The authors thank $\mathrm{K}$. Kreiss (National Institute for Occupational Safety and Health, Morgantown WV, USA) and B. Zhen (Response Oncology, Memphis, TN, USA) for their help at the beginning of the project. The authors would also like to thank K.M. O'Donnell for editing the manuscript.
}

\section{References}

1. Saltini C, Winestock K, Kirby M, Pinkston P, Crystal RG. Maintenance of alveolitis in patients with chronic beryllium disease by beryllium specific helper T-cells. $N$ Engl J Med 1989; 320: 1103-1109.

2. Rossman MD, Kern JA, Elias JA, et al. Proliferative response of bronchoalveolar lymphocytes to beryllium. A test for chronic beryllium disease. Ann Int Med 1988; 108: 687-693.

3. Pappas GP, Newman LS. Early pulmonary physiologic abnormalities in beryllium disease. Am Rev Respir Dis 1993; 148: 661-666.

4. Newman LS, Lloyd J, Daniloff E. The natural history of beryllium sensitization and chronic beryllium disease. Env Health Perspect 1996; 104: 937-943. 
5. Richeldi L, Sorrentino R, Saltini C. HLA-DPB1 glutamate 69: a genetic marker of beryllium disease. Science 1993; 262: 242-244.

6. Richeldi L, Kreiss K, Mroz MM, Boguang Z, Tartoni $P$, Saltini C. Interaction of genetic and exposure factors in the prevalence of berylliosis. $\mathrm{Am} \mathrm{J}$ Ind Med 1997; 32: 337-340.

7. Wang Z, White PS, Petrovic M, et al. Differential susceptibilities to chronic beryllium disease contributed by different Glu69 HLA-DPB1 and -DPA1 alleles. J Immunol 1999; 163: 1647-1653.

8. Lombardi G, Germani C, Uren J, et al. DP allelespecific $\mathrm{T}$ cell responses to beryllium account for DPassociated susceptibility to chronic beryllium disease. J Immunol 2001; 166: 3549-3555.

9. Martinetti M, Tinelli C, Kolek V, et al. "The sarcoidosis map": a joint survey of clinical and immunogenetic findings in two European countries. Am J Respir Crit Care Med 1995; 152: 557-564.

10. Kreiss K, Mroz MM, Zhen B, Wiedemann H, Barna B. Risks of beryllium disease related to work processes at a metal, alloy, and oxide production plant. Occup Environ Med 1997; 54: 605-612.

11. Voorter CEM, Rozemuller EH, De Bruyn-Geraets D, Van der Zwan AW, Tilanus MGJ, Van den BergLoonen EM. Comparison of DRB sequence based typing using different strategies. Tissue Antigens 1997; 49: 471-476.

12. Voorter CEM, Kik MC, Van den Berg-Loonen EM. High resolution HLA typing for the DQB1 gene by sequence-based typing. Tissue Antigens 1998; 51: 8087.

13. Voorter C, Richeldi L, Gervais T, Van den BergLoonen E. Identification of two new DPB1 alleles, DPB $1 * 7701$ and $* 7801$, by sequence-based typing. Tissue Antigens 1998; 52: 190-192.

14. Svejgaard A, Ryder LP. HLA and disease associations: detecting the strongest association. Tissue Antigens 1994; 43: 18-27.

15. Ottenhoff TH, Gonzalez NM, de Vries RR, Convit J, van Rood JJ. Association of HLA specificity LB-E12 (MB1, DC1, MT1) with lepromatous leprosy in a Venezuelan population. Tissue Antigens 1984; 24: $25-$ 29.

16. Zerva L, Cizman B, Mehra NK, et al. Arginine at positions 13 or $70-71$ in pocket 4 of HLA-DRB1 alleles is associated with susceptibility to tuberculoid leprosy. J Exp Med 1996; 183: 829-836.

17. Hirayama K, Matsushita S, Kikochi I, Iuchi M, Ohta N, Sasezuki T. HLA-DQ is epistatic to HLA-DR in controlling the immune response to schistosomal antigen in humans. Nature 1987; 327: 426-430.

18. Hirayama $\mathrm{K}$, Chen $\mathrm{H}$, Kikuchi $\mathrm{M}$, et al. HLA-DRDQ alleles and HLA-DP alleles are independently associated with susceptibility to different stages of post-schistosomal hepatic fibrosis in the Chinese population. Tissue Antigens 1999; 53: 269-274.

19. Sinigaglia F, Hammer J. Motifs and supermotifs for MHC class II binding peptides. J Exp Med 1995; 181: 449-451.

20. Diaz G, Catalfamo M, Coiras MT, et al. HLA-DP $\beta$ residue 69 plays a crucial role in allorecognition. Tissue Antigens 1998; 52: 27-36.

21. Fontenot AP, Falta MT, Freed BM, Newman LS, Kotzin BL. Identification of pathogenic T cells in patients with beryllium-induced lung disease. J Immunol 1999; 163: 1019-1026.

22. Potolicchio I, Festucci A, Hausler P, Sorrentino R. HLA-DP molecules bind cobalt: a possible explanation for the genetic association with hard metal disease. Eur J Immunol 1999; 29: 2140-2147.

23. Tinkle SS, Kittle LA, Schumacher BA, Newman LS. Beryllium induces IL-2 and IFN- $\gamma$ in berylliosis. J Immunol 1997; 158: 518-526.

24. Petrovsky N, Harrison LC. HLA class II-associated polymorphism of interferon-gamma production. Implications for HLA-disease association. Hum Immunol 1997; 53: 12-16.

25. Abraham LJ, Kroeger KM. Impact of the -308 TNF promoter polymorphism on the transcriptional regulation of the TNF gene: relevance to disease. J Leukocyte Biol 1999; 66: 562-566.

26. Seitzer U, Swider C, Stuber F, et al. Tumour necrosis factor alpha promoter gene polymorphism in sarcoidosis. Cytokine 1997; 9: 787-790.

27. Zhai R, Jetten M, Schins RP, Franssen H, Borm PJ. Polymorphisms in the promoter of the tumor necrosis factor-alpha gene in coal miners. Am J Ind Med 1998; 34: 318-324.

28. Sawyer RT, Kittle LA, Hamada H, Newman LS, Campbell PA. Beryllium stimulated production of tumor necrosis factor- $\alpha$ by a mouse hybrid macrophage cell line. Toxicology 2000; 143: 235-247.

29. Saricaoglu H, Tunali S, Bulbul E, White IR, Palali Z. Prevention of nickel-induced allergic contact reactions with pentoxifylline. Contact Dermatitis 1998; 39: 244 247.

30. Nicas M, Lomax GP. A cost-benefit analysis of genetic screening for susceptibility to occupational toxicants. J Occup Environ Med 1999; 41: 535-544. 